FOCUS: Journal of International Business Volume 4, Issue 1, January-June 2017, pp. 53-62 doi: $10.17492 /$ focus.v4i01.9540

\title{
Chinese and Indian Middle Level Employees: A Study on Cross Cultural Competencies
}

\author{
R. Delecta Jenifer* and G.P. Raman**
}

\begin{abstract}
Cultural competence is the capability of an individual to work efficiently with people from different cultural backgrounds. Culturally competent employees become globally proficient. We aim to assess the cultural competence among middle management employees from footwear companies in China and India. This study design is a cross sectional survey method using cross cultural competence inventory. We collected data from 30 middle management employees each from China and India. This study examined the relationship between demographic factors and cross-cultural competence within those countries and then conducted a comparison between China and India. The results reveal that higher education level and increased work experience leads to higher level of cross cultural competence.
\end{abstract}

Keywords: Cross cultural competence; Organization; Education; Middle level employees; China; India.

\subsection{Introduction}

Cross cultural competence or transcultural competence has been defined by many scholars. Trompenaars and Hampden- Turner (2002) argue that business cultures are so different to be in some respects diametrically opposed and that because is run differently around the globe, we need different managerial and leadership competencies. At the same time, from those differences, there is an emerging new capacity for bridging differences, which they call as transcultural competence.

*Corresponding author; Research Scholar, Department of Management Studies, Sri Chandrasekharendra Saraswathi Viswa Mahavidyalaya University, Kanchipuram, Tamil Nadu, India. (Email id: delecta123@gmail.com)

**Controller of Examinations, Sri Chandrasekharendra Saraswathi Viswa Mahavidyalaya University, Kanchipuram, Tamil Nadu, India (Email id: drgpraman@gmail.com) 
Both Chinese and Indians are collectivistic in nature. Cultural competence can be simply described as the ability to understand the needs and norms of populations different from one's own (Kumasi and Hill, 2013). Becoming culturally competent is a development process (Cross, 1989). This study aims to assess the cultural competence among middle management employees from footwear companies in China and India

\subsection{Review of Literature}

Culture is basically defined as the product of any human association where individuals meet, communicate, and interact, and in doing so, individuals create cultures (Durkhaim, 1956).Many researchers have defined cross cultural competence and various models has been established in this respect. Johnson, Lenartowicz, \& Apud (2006) define cross-cultural competence (3C) as an individual's ability to work successfully with people from different national cultural backgrounds. Developing cross-cultural competence is a process which involves methods and procedures dedicated to evolving cross-cultural competence that leads to the adoption and understanding of the features of one's own culture, develops a positive attitude to other cultural groups and its participants, and increases the ability to understand and interact with them (Stefanenkon and Kupavskaya, 2012).

Various models of cross-cultural competence have been proposed by different authors. Cross (1989) emphasised three critical elements in his model of cultural competence: self-awareness; culture-specific knowledge; and skills promoting effective socio-cultural interactions by an individual. His model has been widely cited and used as the conceptual framework for cultural competence. The KSA model of cross-cultural competence (Abbe et al., 2007) relies on Knowledge/cognition; Skills; and Affect (motivation). The 'Knowledge' dimension includes cultural awareness, cross-cultural schema and cognitive complexity. The 'Skill' dimension includes interpersonal skills, self-regulation and flexibility. The 'Affect' dimension includes attitude, initiative, empathy and low need for closure. Ross et al. (2009) proposed cross-cultural competence inventory with dimensions including willingness to engage, cognitive flexibility and openness, emotional regulation, tolerance of uncertainty, self-efficacy and ethno-cultural empathy.

\subsection{Methodology}

\subsection{Study design and setting}

The study design is cross sectional survey using data collected from footwear companies in China and India. The population of the study were middle management 
employees from footwear companies in China and India. All the employees were adults aged 25 years and more. This study involved 60 employees. Participants were eligible for inclusion in the study if they are employees from the same company. Participants were excluded if they did not meet the inclusion criteria.

\subsection{Instruments of study}

This study used cross cultural competence inventory model (CCCI) developed by Ross et.al (2009) to assess the cross-cultural competence among employees from Footwear Companies in China and India. The instruments of this study include three parts: (i) participants' demographic characteristics related to subject's socio demographic background including gender, age, education, profession, department, experience in the work, annual income. ii) human resource development practices (iii) the cross-cultural competence part explored the cross-cultural competence assessment. This part has seven subgroups such as cultural adaptability, determination, tolerance of uncertainty, selfpresentation, mission focus, engagement and lie scale. The cultural adaptability, determination, self-presentation, mission focus, engagement and lie scale were assessed through 18 items, 6 items, 4 items, 7 items, 11 items and 5 items respectively, and using the following Likert scale design (1=strongly disagree, $2=$ disagree, $3=$ neutral, $4=$ agree, and 5=strongly agree). A reverse coding was used for tolerance of uncertainty with 11 items ( $5=$ strongly disagree, $4=$ disagree, $3=$ neutral, $2=$ agree, and $1=$ strongly agree.

\subsection{Data collection plan}

The data collection was done on the basis of study sample with employees' consent. Questionnaires were submitted in an interview format and the objectives of the survey were clearly explained. Data collection has been done by well-trained managers. At the end of the interview the questionnaire was revised to ensure that all items completed. The data was compiled by the investigated for result analysis. Data was collected from May $1^{\text {st }}$ to May $15^{\text {th }}, 2017$ in China and from May $16^{\text {th }}$ to June $1^{\text {st }} 2017$ in India. The IBM SPSS version24 was used for data analysis. The data analysis included correlation tests for the cross-cultural competence dimensions of China, India and t-test.

\subsection{Results}

\subsection{Demographic profile}

Out of 30 Indian participants $83,3 \%$ were male and $60 \%$ aged 36 to 45 years old. In terms of education level $60 \%$ of the population had master degree and $60 \%$ from administration department. Around $70 \%$ of population were under 6 years' experience 
and $43.3 \%$ were managers (Table 1) Out of 30 Chinese participants $43.3 \%$ were male and $73.3 \%$ were aged above 36 years old. Around $66.7 \%$ were HSC qualified and $3.3 \%$ were master degree qualified. Around 56.75 were managers and $46.7 \%$ were from administration and $96.6 \%$ were more than 10 years experienced (Table 1 ).

Table 1: Demographic Profile of Indian and Chinese Middle Level Employees

\begin{tabular}{|c|c|c|c|c|c|}
\hline \multicolumn{3}{|c|}{ India } & \multicolumn{3}{|c|}{ China } \\
\hline $\mathrm{n}=30$ & Frequency & Percent & $\mathrm{n}=30$ & Frequency & Percent \\
\hline Gender & & & Gender & & \\
\hline Male & 25 & 83.3 & Male & 13 & 43.3 \\
\hline Female & 5 & 16.7 & Female & 17 & 56.7 \\
\hline Age & & & Age & & \\
\hline $25-35$ & 12 & 40 & $25-35$ & 8 & 26.7 \\
\hline \multirow[t]{2}{*}{$36-45$} & 18 & 60 & $36-45$ & 18 & 60 \\
\hline & & & 46 Above & 4 & 13.3 \\
\hline Education & & & Education & & \\
\hline HSC & 2 & 6.7 & JHS & 3 & 10 \\
\hline Bachelor & 10 & 33.3 & HSC & 20 & 66.7 \\
\hline \multirow[t]{2}{*}{ Master } & 18 & 60 & Bachelor & 6 & 20 \\
\hline & & & Master & 1 & 3.3 \\
\hline Department & & & Department & & \\
\hline Manufacturing & 5 & 16.7 & Manufacturing & 10 & 33.3 \\
\hline Administration & 18 & 60 & Administration & 14 & 46.7 \\
\hline Functional & 7 & 23.3 & Functional & 6 & 20 \\
\hline Position & & & Position & & \\
\hline Supervisor & 12 & 40 & Senior Manager & 4 & 13.3 \\
\hline Manager & 13 & 43.3 & Manager & 17 & 56.7 \\
\hline Senior Manager & 5 & 16.7 & Supervisor & 9 & 30 \\
\hline $\begin{array}{l}\text { Work } \\
\text { Experience }\end{array}$ & & & $\begin{array}{l}\text { Work } \\
\text { experience }\end{array}$ & & \\
\hline Less 6 & 21 & 70 & less 6 & 1 & 3.3 \\
\hline \multirow[t]{3}{*}{6 to 10} & 9 & 30 & 6 to 10 & 18 & 60 \\
\hline & & & $21-30$ & 10 & 33.3 \\
\hline & & & Above 35 & 1 & 3.3 \\
\hline
\end{tabular}

Source: Primary survey 


\subsection{Cross cultural competence}

The mean score of Indian employees (Table 2) for human resource development, cultural adaptability, determination, tolerance of uncertainty, self-presentation, mission focus, engagement, and lie scale were $5.00 \pm 0.000,77.00 \pm 4.742,25.30 \pm 2.246$, $20.93 \pm 4.616,15.67 \pm 3.527,30.20 \pm 2.511,47.50 \pm 3.785,19.57 \pm 3.910$ respectively. The total score of cross cultural competence ranged from 204 to 258 with mean score of $236.17 \pm 11.537$. The mean score of Chinese employees (Table 3 ) for human resource development, cultural adaptability, determination, tolerance of uncertainty, selfpresentation, mission focus, engagement, and lie scale were $4.33 \pm 0.661,69.07 \pm 5.735$, $20.00 \pm 2.971,25.43 \pm 4.199,10.60 \pm 2.283, \quad 27.13 \pm 2.862, \quad 38.10 \pm 2.820, \quad 12.83 \pm 2.437$ respectively. The total cross-cultural competence ranged from 174 to 221 with the mean score of $203.17 \pm 11.585$.

Table 2: Mean Score of Cross Cultural Competence - Indian Middle Level Employees

\begin{tabular}{|l|c|c|c|c|}
\hline \multicolumn{1}{|c|}{ Dimension } & Min & Max & Mean & s.d. \\
\hline Human Resource Development & 5 & 5 & 5.00 & 0.000 \\
\hline Cultural Adaptability & 66 & 87 & 77.00 & 4.742 \\
\hline Determination & 20 & 29 & 25.30 & 2.246 \\
\hline Tolerance of Uncertainty & 13 & 34 & 20.93 & 4.616 \\
\hline Self-Presentation & 6 & 19 & 15.67 & 3.527 \\
\hline Mission Focus & 23 & 35 & 30.20 & 2.511 \\
\hline Engagement & 37 & 54 & 47.50 & 3.785 \\
\hline Lie Scale & 11 & 25 & 19.57 & 3.910 \\
\hline Cross Cultural Competence & 204 & 258 & 236.17 & 11.537 \\
\hline
\end{tabular}

Table 3: Mean Score of Cross Cultural Competence - Chinese Middle Level Employees

\begin{tabular}{|l|c|c|c|c|}
\hline \multicolumn{1}{|c|}{ Dimension } & Min & Max & Mean & s.d \\
\hline Human Resource Development & 2 & 5 & 4.33 & 0.661 \\
\hline Cultural Adaptability & 57 & 82 & 69.07 & 5.735 \\
\hline Determination & 14 & 25 & 20.00 & 2.971 \\
\hline Tolerance of Uncertainty & 18 & 36 & 25.43 & 4.199 \\
\hline Self-Presentation & 6 & 15 & 10.60 & 2.283 \\
\hline Mission Focus & 23 & 35 & 27.13 & 2.862 \\
\hline Engagement & 33 & 45 & 38.10 & 2.820 \\
\hline Lie Scale & 7 & 17 & 12.83 & 2.437 \\
\hline Cross Cultural Competence & 174 & 221 & 203.17 & 11.585 \\
\hline
\end{tabular}




\subsection{Correlation between demographic profile and cross-cultural competence}

Various correlations were found between demographic and cross-cultural competence variables for Indian and Chinese employees (Table 4). The work experience was positively correlated with tolerance of uncertainty $(\mathrm{r}=0.367, \mathrm{p}=0.004)$. The education was positively correlated with self-presentation $(\mathrm{r}=0.493 \mathrm{p}=0.0001)$, mission focus $(r=0.499 \mathrm{p}=0.0001)$. positive correlation was found between all the cross-cultural competences except tolerance of uncertainty $(r=0.471 \mathrm{p}=0.0001)$.

Table 4: Pearson Correlation for Cross Cultural Competence Dimensions and Demographic Performance of India and China

\begin{tabular}{|c|c|c|c|c|c|c|c|c|c|c|c|}
\hline & $\mathbf{1}$ & $\mathbf{2}$ & $\mathbf{3}$ & $\mathbf{4}$ & $\mathbf{5}$ & $\mathbf{6}$ & $\mathbf{7}$ & $\mathbf{8}$ & $\mathbf{9}$ & $\mathbf{1 0}$ & $\mathbf{1 1}$ \\
\hline $\mathbf{1}$ & 1 & & & & & & & & & & \\
\hline $\mathbf{2}$ & $-.787^{* *}$ & 1 & & & & & & & & & \\
\hline $\mathbf{3}$ & $-.563^{* *}$ & $.506^{* *}$ & 1 & & & & & & & & \\
\hline $\mathbf{4}$ & $-.511^{* *}$ & $.574^{* *}$ & $.525^{* *}$ & 1 & & & & & & & \\
\hline $\mathbf{5}$ & $-.645^{* *}$ & $.547^{* *}$ & $.563^{* *}$ & $.671^{* *}$ & 1 & & & & & & \\
\hline $\mathbf{6}$ & $.367^{* *}$ & $-.395^{* *}$ & $-.344^{* *}$ & $-.538^{* *}$ & $-.626^{* *}$ & 1 & & & & & \\
\hline $\mathbf{7}$ & $-.580^{* *}$ & $.493^{* *}$ & $.430^{* *}$ & $.471^{* *}$ & $.691^{* *}$ & $-.650^{* *}$ & 1 & & & & \\
\hline $\mathbf{8}$ &.$- .446^{* *}$ & $.499^{* *}$ & $.474^{* *}$ & $.689^{* *}$ & $.597^{* *}$ & $-.451^{* *}$ & $.469^{* *}$ & 1 & & & \\
\hline $\mathbf{9}$ &.$- .732^{* *}$ & $.662^{* *}$ & $.574^{* *}$ & $.753^{* *}$ & $.792^{* *}$ & $-.570^{* *}$ & $.684^{* *}$ & $.663^{* *}$ & 1 & & \\
\hline $\mathbf{1 0}$ & $-.564^{* *}$ & $.490^{* *}$ & $.360^{* *}$ & $.531^{* *}$ & $.625^{* *}$ & $-.646^{* *}$ & $.674^{* *}$ & $.434^{* *}$ & $.696^{* *}$ & 1 & \\
\hline $\mathbf{1 1}$ & $-.716^{* *}$ & $.666^{* *}$ & $.594^{* *}$ & $.853^{* *}$ & $.846^{* *}$ & $-.554^{* *}$ & $.739^{* *}$ & $.758^{* *}$ & $.933^{* *}$ & $.758^{* *}$ & 1 \\
\hline
\end{tabular}

**Correlation is significant at the 0.01 level (2-tailed).

Note: The numbers stand for the following dimensions:

1. Work experience; 2. Education; 3. HRD; 4. Cultural adaptability; 5. Determination; 6. Tolerance of uncertainty; 7. Self-presentation; 8. Mission focus; 9. Engagement; 10; Lie scale; 11. Cross-cultural competence

\subsection{Comparison of cross-cultural competence: India and China}

Seven $t$ tests (Table 5) show statistically significant differences between Indian and Chinese employees in all the dimensions of cross cultural competence. On cultural adaptability dimensions $\mathrm{t}=5.84 \mathrm{p}<.05$, the Indian middle management employees mean scores on cultural adaptability $(\mathrm{M}=77 \mathrm{~s} . \mathrm{d}=4.74)$ were higher than Chinese employees $(\mathrm{M}=69.07$, s.d=5.74). On determination dimension $\mathrm{t}=7.79, \mathrm{p}<.05$ with determination scores for Indian employees $(M=25.30, s . d=2.25)$ being higher than Chinese employees 
$(\mathrm{M}=20.00$, s. $\mathrm{d}=2.97)$ On Tolerance of uncertainty dimension $\mathrm{t}=-3.95, \mathrm{p}<.05$ with tolerance of uncertainty scores for Indian employees $(M=20.93$, s.d=4.62) being lower than Chinese employees ( $M=25.43$, s. $d=4.20)$. On self-presentation Dimension $t=6.61$, $\mathrm{p}<.05$ with self-presentation scores for Indian employees $(\mathrm{M}=15.67$, s.d $=3.53)$ being higher than Chinese employees $(M=10.60, \mathrm{~s} . \mathrm{d}=2.28)$.

Table 5: Test of Mean Difference for the Dimensions of Cross Cultural Competence

\begin{tabular}{|c|c|c|c|}
\hline Dimension & Mean & s.d & $\mathbf{t}$ \\
\hline \multicolumn{4}{|c|}{ Human Resource Management } \\
\hline India & 5.00 & 0.00 & \multirow[t]{2}{*}{5.53} \\
\hline China & 4.33 & 0.66 & \\
\hline \multicolumn{4}{|c|}{ Cultural Adaptability } \\
\hline India & 77.00 & 4.74 & \multirow[t]{2}{*}{5.84} \\
\hline China & 69.07 & 5.74 & \\
\hline \multicolumn{4}{|c|}{ Determination } \\
\hline India & 25.30 & 2.25 & \multirow[t]{2}{*}{7.79} \\
\hline China & 20.00 & 2.97 & \\
\hline \multicolumn{4}{|c|}{ Tolerance of Uncertainty } \\
\hline India & 20.93 & 4.62 & \multirow[t]{2}{*}{-3.95} \\
\hline China & 25.43 & 4.20 & \\
\hline \multicolumn{4}{|c|}{ Self-Presentation } \\
\hline India & 15.67 & 3.53 & \multirow[t]{2}{*}{6.61} \\
\hline China & 10.60 & 2.28 & \\
\hline \multicolumn{4}{|c|}{ Mission Focus } \\
\hline India & 30.20 & 2.51 & \multirow[t]{2}{*}{4.41} \\
\hline China & 27.13 & 2.86 & \\
\hline \multicolumn{4}{|l|}{ Engagement } \\
\hline India & 47.50 & 3.79 & \multirow[t]{2}{*}{10.91} \\
\hline China & 38.10 & 2.82 & \\
\hline \multicolumn{4}{|l|}{ Lie Scale } \\
\hline India & 19.57 & 3.91 & \multirow[t]{2}{*}{8.01} \\
\hline China & 12.83 & 2.44 & \\
\hline \multicolumn{4}{|c|}{ Cross Cultural Competence } \\
\hline India & 236.17 & 11.54 & \multirow[t]{2}{*}{11.05} \\
\hline China & 203.17 & 11.59 & \\
\hline
\end{tabular}


On Engagement dimensions $\mathrm{t}=10.91 \mathrm{p}<.05$ With engage On Mission focus dimensions $\mathrm{t}=4.41, \mathrm{p}<.05$ with mission focus scores for Indian employees $(\mathrm{M}=30.20$, $\mathrm{s} . \mathrm{d}=2.51)$ being higher than Chinese employees $(\mathrm{M}=27.13$, $\mathrm{s} . \mathrm{d}=2.86)$.ment scores of Indian employees $(M=47.50, s . d=3.79)$ higher than Chinese employees $(M=38.10$, s.d $=2.82$ on lie scale Dimensions $\mathrm{t}=8.01 \mathrm{p}<.05$ with lie scale scores of Indian employees $(M=19.57$ s.d=3.91) higher than Chinese employees $(M=12.83$, s.d=2.44). overall crosscultural competence score $\mathrm{t}=11.05 \mathrm{p}<.05$ with cross cultural competence scores of Indian employees $(M=236.17, s . d=11.54)$ higher than Chinese employees $(M=203.17$, s.d=11.59).

\subsection{Discussion}

This study demonstrates that demographic characters are increasing cross cultural competence (CCC) in internal business environment. This study can't be generalized for entire factory as the sample size is low. This is to understand the initial cross-cultural competence levels between Indian and Chinese employees and how this could be improved in footwear companies. Indian participants had less than 10 years' experience and higher education level where as Chinese participants had 10-35 years of experience band with lower education levels. This study shows that increase work experience has positive correlation with tolerance of uncertainty. Also, education level, self-presentation and mission focus were positively correlated. A previous study has observed similarity with our study that personal experience is associated with cultural awareness (Black and Duhon, 2006). Another study finds that education level tends to be associated with leadership role with cross cultural skills (Wheelan, Buzaglo and Tsumura, 1998). A study by Schim, Doorenbos, and Borse (2005) demonstrates that there is a positive correlation between educational attainment level and cultural competence. Johnson et al. (2006) also report that skills, knowledge, and attributes are necessary for cultural competence.

We find that there is no significant difference between Indian and Chinese participants' cross cultural competencies. However, t-scores show that except tolerance of uncertainty, mean and standard deviation values are higher for Indian participants than Chinese participants. This implies that education level of Indian participants and natural cultural values are impacting cross cultural competencies. Chinese participants had higher mean and standard deviation in tolerance of uncertainty because of their work experience is longer than Indian participants. This study is consistent with earlier studies emphasising the importance of national culture and ethnicity in accessing cross cultural competence (Hughes, 1971; Jarvenpaa and Leidner, 1999, Watson et al, 1993). A 
previous study reported in particular that the mean scores increased with level of education (Cicolini et al., 2015). Many previous studies have reported that, cross cultural competent employee increase the performance and are successful in multicultural environments.

\subsection{Conclusion and Implications}

This article provides new outlook on cross cultural competence between India and China middle management in footwear companies. This cross-cultural competence (CCC) model describes that, how the demographic factors are impacting cross-cultural competencies. This study provides experimental support for the cross-cultural competence and demographic relationship. It also attempts to illuminate the relationship between national cultures and cross-cultural competence. The study conducted experimental investigations of cross-cultural competence - demographic paradigm in cross cultural situations.

In the recent trends of increased diversity of working place, middle level and top level managers must be competent in cross-culture skills to bring the successful performance of individual and team. The cultural adaptability, mission focus and tolerance of uncertainty can be increased by education and training. This paper underwrites to the discussion about the need of training program to be more effective to manage cultural conflicts in working place. Additionally, cultural audits including nationality, native language, race, religion or beliefs, educational levels and work performance can be done to develop culturally competent organisation. Cross-cultural competence in global environment has been key area for studies and understanding how to enhance cross cultural competence of team is the dominant goal of organisation research. Researchers can do advanced study on cross cultural competence and how that can be effectively applied to develop multicultural team. Effective cross-cultural teams can reduce the international operating costs and operation failure and can improve the multi-ethnic understanding.

\section{References}

Black, H. T., \& Duhon, D. L. (2006). Assessing the impact of business study abroad programs on cultural awareness and personal development. Journal of Education for Business, 81(3), 140-144. 
62 FOCUS: Journal of International Business, Volume 4, Issue 1, January-June 2017

Cicolini, G., Della Pelle, C., Comparcini, D., Tomietto, M., Cerratti, F., Schim, S. M., \& Simonetti, V. (2015). Cultural competence among Italian nurses: A multicentric survey. Journal of Nursing Scholarship, 47(6), 536-543.

Cross, T. L. (1989). Towards a culturally competent system of care: A Monograph on effective services for minority children who are severely emotionally disturbed. CASSP Technical Assistance Center. Retrieved from https://archive.org/details/towardscultural 100un

Durkheim, E. (1956). Education and sociology (1st ed.). New York, NY: The Free Press.

Johnson, J.P., Lenartowicz, T., Salvador, A. (2006). Cross-cultural competence in international business: Toward a definition and a model. Journal of International Business Studies, 37(4), 525-543.

Maxwell, S. E., \& Delaney, H. D. (2004). Designing Experiments and Analyzing Data: A Model Comparison Perspective (vol. 1). Hove, East Sussex: Psychology Press.

Ross, K., Thornson, C. A., McDonald, D. P., \& Arrastia, M. C. (2009). The development of the CCCI: The cross-cultural competence inventory. Unpublished manuscript, Defense Equal opportunity Management Institute (DEOMI), Patrice Air Force Base, FL. Retrieved from https://www. deomi. org/contribute/EOEEOResources/documents/ Development_of_the_CCCI-Ross.pdf.

Schim, S. M., Doorenbos, A. Z., \& Borse, N. N. (2005). Cultural competence among Ontario and Michigan healthcare providers. Journal of Nursing Scholarship, 37(4), 354360 .

Stefanenko, T., \& Kupavskaya, A. (2012). Developing Cross-cultural Competence. In Encyclopedia of the Sciences of Learning (pp. 941-944). US: Springer.

Trompenaars, A., \& Hampden-Turner, C. (2002). 21 Leaders for the 21st Century: How Innovative Leaders Manage in the Digital Age. US: McGraw-Hill Companies.

Wheelan, S. A., Buzaglo, G., \& Tsumura, E. (1998). Developing assessment tools for cross-cultural group research. Small Group Research, 29(3), 359-370. 